\title{
Interventions to lower the glycemic response to carbohydrate foods with a low-viscosity fiber (resistant maltodextrin): meta-analysis of randomized controlled trials ${ }^{1-4}$
}

\author{
Geoffrey Livesey and Hiroyuki Tagami
}

\begin{abstract}
Background: The glycemic response to diet has been linked with noncommunicable diseases and is reduced by low-palatable, viscous, soluble fiber (1). Whether a palatable, low-viscous, soluble fiber such as resistant maltodextrin (RMD) has the same effect is unclear. Objective: The objective was to assess evidence on the attenuation of the blood glucose response to foods by $\leq 10 \mathrm{~g}$ RMD in healthy adults.
\end{abstract}

Design: We conducted a systematic review of randomized, placebocontrolled trials with the use of fixed- and random-effects metaanalyses and meta-regression models.

Results: We found data from 37 relevant trials to April 2007. These trials investigated the attenuation of the glycemic response to rice, noodles, pastry, bread, and refined carbohydrates that included 30$173 \mathrm{~g}$ available carbohydrate. RMD was administered in drinks or liquid foods or solid foods. Placebo drinks and foods excluded RMD. Percentage attenuation was significant, dose-dependent, and independent of the amount of available carbohydrate coingested. Attenuation of the glycemic response to starchy foods by $6 \mathrm{~g}$ RMD in drinks approached $\approx 20 \%$, but when placed directly into foods was $\approx 10 \%$ - significant $(P<0.001)$ by both modes of administration. Study quality analyses, funnel plots, and trim-andfill analyses uncovered no cause of significant systematic bias. Studies from authors affiliated with organizations for-profit were symmetrical without heterogeneity, whereas marginal asymmetry and significant heterogeneity arose among studies involving authors from nonprofit organizations because of some imprecise studies.

Conclusions: A nonviscous palatable soluble polysaccharide can attenuate the glycemic response to carbohydrate foods. Evidence of an effect was stronger for RMD in drinks than in foods. Am J Clin Nutr 2009;89:114-25.

\section{INTRODUCTION}

In 1998 the World Health Organization (WHO)/Food and Agriculture Organization (FAO) recommended that the food industry attempt to lower the glycemic response to foods and diets (1). Subsequent evidence supports their recommendation. Systematic reviews of intervention studies (2-4) have shown that foods with a low glycemic index or load can help to normalize the fasting blood glucose concentration, improve glycated protein concentrations, and elevate insulin sensitivity in diabetic and nondiabetic subjects $(2,5)$. Such is apparent both independently of the dietary fiber content of foods according to AOAC International or equivalent methods and independently of a change in dietary energy density $(2,6)$. Observational studies assessed meta-analytically support a hypothesis that carbohydrate foods with a high glycemic index contribute to the progression of several diseases (7). Lowering the glycemic load to $\approx 100 \mathrm{~g}$ (glucose equivalents) per day without elevating fat intake would appear most effective as a modifier of glycemic control in both interventional (2) and observational studies $(\mathrm{G}$ Livesey, unpublished data, 2008). Although there is no global consensus on issues related to glycemic response and health, increasing evidence supports the view taken by the WHO/FAO (1).

Evidence that viscous soluble fiber can lower the glycemic response to carbohydrate foods is well known; however, such polysaccharides have limited palatability (8-11). Whether a palatable, nonviscous, soluble fiber might reduce postprandial glycemia is unclear. Whether any reduction would be dependent on the food or drink coingested is also unclear. Resistant maltodextrin (RMD) is a nonviscous fiber (12-14), and preliminary evidence indicates that it may help control postprandial glycemia $(15,16)$. In Japan, foods and drinks including RMD have status as foods for special health use (FOSHU) $(17,18)$. The present review was conducted for several reasons. First, worldwide, especially in North America and Europe, there is an increasing prevalence of disease related to poor glycemic control. Second, RMD is used in North America and Europe, but information from these places is limited. Third, evidence on the possible utility of RMD in Japan comes from the study of its effect on the height of the glycemic response. However, in Western countries the effect on the incremental area under the curve (IAUC) for the glucose response is considered the most important summary statistic (1, $19,20)$ relevant to health and to glycemic control $(2-7)$. Herein, for the first time, we calculated and presented the effects on the

\footnotetext{
${ }^{1}$ From Independent Nutrition Logic, Pealerswell House, Wymondham, Norfolk, United Kingdom (GL), and Matsutani Chemical Industry Co, Ltd, Itami City, Japan (HT).

${ }^{2}$ The opinions expressed herein are those of the authors and do not necessarily represent the views of the Matsutani Chemical Industry Co, Ltd.

${ }^{3}$ The review was both commissioned from Independent Nutrition Logic Ltd and funded by the Matsutani Chemical Industry Co, Ltd, Itami City, Japan.

${ }^{4}$ Address reprint requests and correspondence to G Livesey, Independent Nutrition Logic, Pealerswell House, 21 Bellrope Lane, Wymondham, Norfolk NR18 0QX, United Kingdom. E-mail: glivesey@inlogic.co.uk.

Received August 14, 2008. Accepted for publication October 14, 2008.

First published online December 3, 2008; doi: 10.3945/ajen.2008.26842.
} 
area responses for a large body of evidence. Fourth, no systematic review or meta-analysis of the information related to glycemia has been reported for any nonviscous polysaccharide. Fifth, there is a large body of evidence on RMD that allows a distinction between different modes of administration in foods or in drinks. Sixth, much of the information on RMD is not available in fully English language journals; therefore, the present review makes this science more accessible.

\section{METHODS}

Electronic databases were searched for studies on GRAS (Generally Recognized as Safe) status of RMD (CFR 21, 1841277). These databases included the Cochrane Central Register of Controlled Trials (CENTRAL) to January 2007 (www.mrw. interscience.wiley.com/cochrane/cochrane_clcentral_articles_fs.html), the US National Library of Medicine database (MEDLINE via the PubMed portal) from 1950 to April 2007 (www.ncbi.nml. nih.gov.80/sites/entrez), Elsevier's Science-Specific Search Engine (SCIRUS) to April 2007; www.scirus.com), Blackwell's Nutrition and Food Science database underpinned by the Commonwealth Agricultural Bureau International (CABI) from 1981 to April 2007 (www.nutritionandfoodsciences.org/), the Japanese Science and Technology Agency database (JMEDPlus; http://pr.jst.go.jp/jdream2/), the National Institute of Informatics Electronic Library Service and National Diet Library (NII-ELS and NDL via their Citations Index portal (CiNii) from their start (before RMD production in 1990) to April 2007 (http://ci. nii.ac.jp/cinii/servlet/CiNiiTop?USELANG=en), and the Matsutani Chemical Co, Ltd collection (nonelectronic). All field searches for "resistant maltodextrin" or "nondigestible dextrin" or "indigestible dextrin" [or by trade name "pinefiber(re)" or "fiber(re)sol"] were performed on each search engine. Searches for "nan-syoka-sei-dekisutorin" (resistant maltodextrin) using both Chinese characters and Japanese katakana were also made on the CiNii and JMEDPlus search engines. We examined publications in English (GL) and foreign languages (HT) for additional studies. Data on glycemic and insulinemic responses were available to both HT and GL as original tables and figures, which transcend (above and independently of) the language barriers. We translated foreign language publications into English, usually fully and sometimes partially to provide transcripts of the methods and results sections only.

We summarized the methods, review processes, and outcomes of inclusion and exclusion criteria (Figure 1). The primary question formulated was, "Does $\leq 10 \mathrm{~g}$ RMD per meal attenuate the postprandial glycemic response to a carbohydrate meal?" The secondary questions asked were as follows: 1) "Does the mode of administration modify any effect size found," 2) "Does any effect observed persist in persons habituated to RMD," and 3) "Does RMD attenuate the postprandial insulin response to dietary carbohydrate"?

Inclusion criteria for the primary question were, for the original studies, defined as randomized controlled trials (RCTs) that 1 ) investigated healthy adult human participants; 2) were interventional without prior adaptation; 3) used defined practical doses of RMD ( $\leq 10 \mathrm{~g}$ per meal); 4 ) provided RMD with a meal, defined by the foods eaten or by their macronutrient composition; 5) had designs controlled with matching placebo, at least single blinded; 6) allowed within-subject comparison between

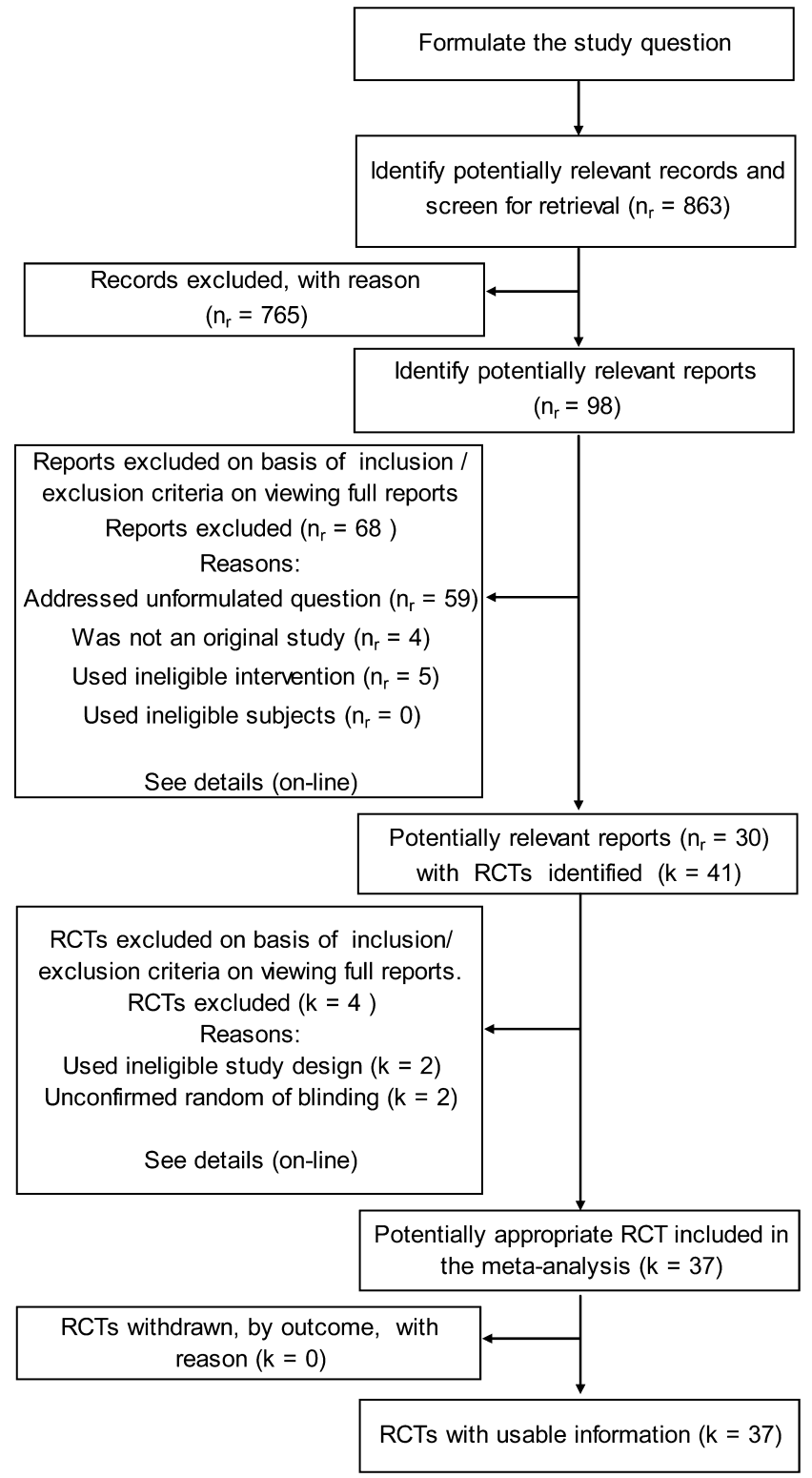

FIGURE 1. Summary of the study methods, review processes, and outcomes of inclusion and exclusion criteria. $n_{\mathrm{r}}$, number of reports; RCTs, randomized controlled trials; $k$, number of RCTs.

treatments; 7) stated the number of participants treated; and 8) measured fasting and postprandial blood glucose (or insulin) for $\geq 2$ $\mathrm{h}$ after RMD ingestion.

RCTs were excluded if they 1 ) repeated (ie, confirming) observations made previously without replacing all individual participants; 2) used a placebo made with available carbohydrate in exchange for the RMD; 3) reduced the availability of food starch by means other than the addition of RMD; 4) had no relevant treatments; 5) by outcome were either associated with a quality item found to have significant bias or were outlying or were unduly influential (see below); and 6 ) used participants adapted to RMD, which we analyzed separately as adapted subjects.

We extracted data on fasting and postprandial blood glucose and insulin into a provisional database constructed in Microsoft Excel (Redmond, WA) before finally preserving it in a Stata database (StataCorp, College Station, TX; see below); an identical 
blank database was used for duplicate extraction. Discrepancies between the 2 databases were identified computationally and resolved by reviewing the publications or translations. We contacted the original authors for clarification and to supply unpublished information when needed (see Acknowledgments).

All studies reported means, SDs, and/or SEEs or 95\% CIs for mean blood glucose and insulin concentrations. Some omissions in error values occurred in the graphical information (for purposes of clarity in presentation); these were obtained by using exact $t$ and $P$ values (21). Most of the authors did not calculate or report means and SEs for incremental areas under the curve (IAUCs) for blood glucose and insulin or differences between areas for the test and control treatment groups. Mean IAUCs from 0 to $120 \mathrm{~min}$ were therefore calculated for each study from the mean blood glucose (or insulin) concentration reported by using the sum of trapezoid rule according to WHO/FAO (1), which excludes areas below baseline. We obtained estimates of the independent (ie, unpaired) SE difference (iSED) between treatments, also according to the trapezoid rule for calculating areas. The within-study SE of the treatment effect-effect of RMD — was the dependent (ie, paired) SE difference, calculated as $\sqrt{\rho \times \text { iSED }^{2}}$, where $\sqrt{\rho}$ would be more recognizable as the ratio of the paired SE difference to the unpaired SE difference. The value of $\sqrt{\rho}$ was considered constant because the interval between treatments in all studies was similar at $\approx 1 \mathrm{wk}$-it may otherwise increase with time. For glucose and insulin, $\sqrt{\rho}$ was equal to 0.21 and 0.40 , respectively. The sensitivity of the combined mean treatment effect-effect size-to potential errors in $\sqrt{\rho}$ was low, at $<1 \%$ of the control treatment IAUC.

The Stata database used for data preservation was also used for input into calculations and meta-analyses (Stata 9SE; StataCorp) by using options under metan, metareg, and metatrim commands (described below). Also used was the nlcom (nonlinear combinations of coefficients) command to evaluate differences between regression coefficients in multiple regressions $\left(\beta_{2} \pm \mathrm{SE}_{2}-\beta_{1} \pm\right.$ $\mathrm{SE}_{1}$; see legend to Figure 2). Results were from random-effects analyses when the among-studies variance, called heterogeneity or $\tau^{2}$, was $>0$. Unexplained heterogeneity $\left(\tau^{2}\right)$ provided a measure of inconsistency in results among studies (more precisely, it is unexplained variance among studies) and can be expressed as the proportion of the total variance within and among studies $\left[I^{2}=\tau^{2} /\left(\mathrm{SE}^{2}+\tau^{2}\right)\right]$. In all analyses, studies were weighted by inverse variance- $1 / \mathrm{SE}^{2}$ for fixed effects and $1 /\left(\mathrm{SE}^{2}+\tau^{2}\right)$ for random effects. In these equalities, $\mathrm{SE}^{2}$ was the square of the within-study SE of the treatment effect (ie, the dependent SE difference given above), and $\tau^{2}$ was the square of the SE among studies - a result generated during meta-analysis.

The significance of variance in results among studies $\left(\tau^{2}>0\right)$ in a meta-analysis was assessed by using the $Q$ test $(P>Q)$ according to the method of DerSimonian and Laird (49). The statistical significance of a combined study mean effect size differing from zero was assessed by using the asymptotic $z$ test $(P>|z|)$. Note that when $P$ is related to $|z|$, vertical lines are used about $z$ to denote a 2 -sided test. In contrast, the $Q$ test is a one-sided chisquare test so that $P>Q$ is unaccompanied by vertical lines.

Meta-regressions were fitted by restricted maximum likelihood (REML option in metareg). The significance of $\tau^{2}>0$ was assessed by using the likelihood ratio test $(P>\chi)$ accompanying metareg. The statistical significance of a trend obtained by combining studies using meta-regression was assessed by using the $t$ test for which Knapp and Hartung's modified SE was used $(P>\mid$ kh-t $\mid)(50)$. The modification inflates the size of the regression coefficient $\mathrm{SE}$ and thus yields a more conservative significance test. Where possible, the significance of a trend was confirmed by using the Monte Carlo permutations test $(P>$ |permute|), which avoids the possibility of spurious assessment of significance due to any deviation from normality in the distribution of the data analyzed (51).

Asymmetry in the distribution of individual study mean effects above and below the combined mean effect size at each level of study precision-given by the independent SE difference-was assessed by using the inverse funnel plot, which reveals publication bias (52). Such possible bias was quantified nonparametrically by using the trim-and-fill analysis (53), which also estimates a possible number of missing studies and their likely positions in the funnel plot. Funnel plot CIs were estimated as $z$ score $\times$ SE for fixed effects and $z$ score $\times \sqrt{\left(\mathrm{SE}^{2}+\tau^{2}\right)}$ for random effects.

Individual study qualities were assessed by using 12 items (see below). Studies meeting a quality item were assigned a result of "yes" (otherwise "no") for each item, the potential total being 12 yeses for each study. The quality items, classified according to the Cochrane Reviews Handbook issued February 2008 (54), covered all 5 common domains of bias: selection (items 1-3), performance (items 4 and 5), attrition (items 6 and 7), detection (items 2, 3, and 8), and reporting (items 9-12). The quality items were as follows: 1) baseline data availability and similarity across treatments; 2) participant randomization; 3) allocation concealment, ie, the randomization result is judged unknown in advance, as with dice or lots used by the participants; 4) double blinding; 5) treatments indistinguishable to the consumer; 6) attrition, ie, participants dropping out or being excluded ( $<20 \%$ of participants); 7$)$ adequate explanations for dropouts and exclusions, 8) crossover design, which is most appropriate to the acute studies; 9) study report addresses potential adverse effects (gastrointestinal discomfort); 10) English language usage, either the whole article or its summary or abstract; 11) nonprofit funding; and 12) setting unbiased, ie, independence of the study participants and the food or ingredient manufacturer (eg, participants recruited from the population at large or an independent institution and not from the food or ingredient manufacturer).

Apart from selecting only placebo-controlled RCTs, no assumption was made beforehand about the potential impact of the quality items. Instead, residuals after explanatory variables (drinks, solids, and dose) were accounted for were analyzed by study quality item and by study quality score (sum of yeses); the former approach being preferred (55). Exclusion of studies by group was planned when the group's combined residuals were significantly different from zero $(P>|z|<0.05)$. Exclusion of individual studies was planned when the study was outlying $(>2.5$ times the SE within study and among studies combined) or unduly influential $\left(\Delta \beta_{\mathrm{ij}}>1\right.$, ie when deleting the study from the analysis affected the size of the regression coefficient by more than one SE) (50).

\section{RESULTS}

\section{Literature search and analysis}

The number ( $k$ ) of RCTs identified was 37 (Figure 1). All ( $k=$ 37) trials were identified via the eastern search engines; none 


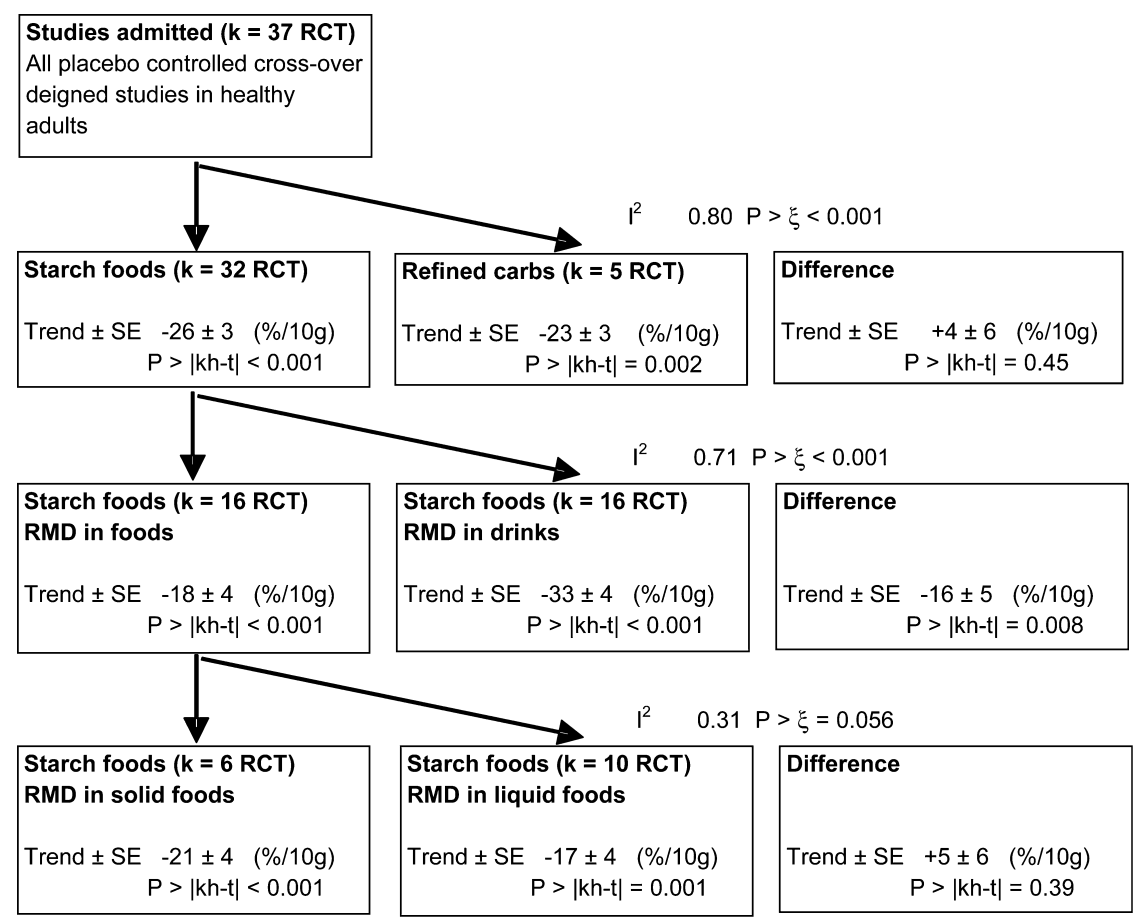

FIGURE 2. Meta-regression analyses of 37 relevant randomized controlled trials (RCTs) that investigated the attenuation of postprandial glycemia in response to 4-10 g resistant maltodextrin (RMD). The 37 usable RCTs (Figure 1) consisted of 32 RCTs with available carbohydrate from starch foods and 5 with available carbohydrate from refined carbohydrates (glucose, sucrose, and maltodextrin) $(22,23)$. RCTs that used starch foods were further divided into 16 RCTs in which the RMD was consumed in drinks $(22,24-36)$ and 16 RCTs in which the RMD was incorporated into solid or liquid foods (31, 37-48). The trends show a decrease in the percentage glycemic response per $10 \mathrm{~g}$ RMD ingested. Estimates of heterogeneity $\left(I^{2}\right.$ or fraction of variation among trial means due to variation among and within studies) are common to estimates in each row. Difference estimates were derived by nonlinear combination of regression coefficients.

were identified with the Western search engines used. All trials had a crossover design and the number of within-subject comparisons totaled 897. All RCTs had a placebo control, but varied in other study quality items (Table 1), as will be considered further below. For individual study details, see "Supplemental Data" in the online issue.

\section{Attenuation of the glycemic response by RMD}

The 37 RCTs consisted of 32 that used starch foods and 5 that used refined carbohydrates (Figure 2). The starch foods included boiled rice or wheat-flour products (noodles, bread rolls, puddings, and sweet pastry) that provided $80-173 \mathrm{~g}$ available carbohydrate with 4-10 g RMD coingested in the starch food or in a drink or liquid food (eg, soup) taken with the starch food. The refined carbohydrate (purified glucose or sucrose or maltodextrin) provided 30-100 g available carbohydrate mixed in solution with 3-10 g RMD. In both the starch and the refined-carbohydrate subgroups, there was significant attenuation that averaged $>20 \%$ l $10 \mathrm{~g}$ RMD and was lower when RMD was ingested instead of the placebo. There were no significant differences between results for the starch and the refined-carbohydrate subgroups (Figure 2).

The 32 RCTs that examined attenuation of the glycemic response to starchy foods were further subgrouped by the mode of administration of RMD (Figure 2). In 16 RCTs the RMD had been incorporated into the starch foods, whereas in another 16 RCTs the RMD had been incorporated into drinks taken with the starch foods. Attenuation was significantly less $(P>|\mathrm{kh}-\mathrm{t}|<$ 0.008) when the RMD was administered within the starch foods ( $\approx 20 \% / 10 \mathrm{~g}$ RMD) than when administered in drinks taken with the starch foods ( $>30 \% / 10 \mathrm{~g} \mathrm{RMD})$.

Because RMD appeared more effective when administered in drinks rather than contained in foods, it was questioned whether the liquid content of foods affected the outcome. However, no significant difference $(P>|\mathrm{kh}-\mathrm{t}|=0.39)$ was observed between solid foods and liquid foods (Figure 2).

Observations in Figure 2 were obtained with regression models that pooled the among-studies variance from each of 2 categories in each row to facilitate the assessment of difference. Results were not sensitive to such pooling because almost identical trends were obtained by examining each subgroup separately (Figure 3).

Studies included in the regression in Figure 3 are shown with open bubbles; those studies excluded for lack of either randomization or blinding or appropriate study design are also shown (gray bubbles). The combined deviation of the excluded studies from the trends for the included studies was $-0.1 \mathrm{SE}$ $5 \%$, which suggests that exclusion would not be a cause of bias.

In all of these analyses (Figures 2 and 3), each trend was ascertained by restricted maximum likelihood random-effects meta-regression; among-studies variance (heterogeneity, $I^{2}$ ) was evident and significant without subgrouping of the studies (Figure 2). Such heterogeneity remained among those studies that administered RMD in drinks when starch foods were consumed and is considered below.

\section{Types of drinks and foods}

The 16 RCTs that used drinks to administer RMD (Figure 2) were further subgrouped by the type of drink: oolong tea, green 
TABLE 1

Attenuation by 3-10 g (adjusted to $6 \mathrm{~g}$ ) resistant maltodextrin (RMD), by type of drink and by source or type of carbohydrate consumed with the drink ${ }^{1}$

\begin{tabular}{|c|c|c|c|c|c|c|}
\hline & $\begin{array}{c}\begin{array}{c}\text { No. of } \\
\text { RCTs }\end{array} \\
k\end{array}$ & $\begin{array}{c}\text { Total no. of } \\
\text { participants in } \\
\text { each study arm } \\
\frac{n}{n}\end{array}$ & \multicolumn{2}{|c|}{$\begin{array}{l}\text { Combined mean } \\
\text { attenuation } \\
\text { from all } k \text { RCTs }\end{array}$} & $\frac{\begin{array}{c}\text { Among-studies } \\
\text { variance }^{3}\end{array}}{I^{2}}$ & Reference \\
\hline & & & \multicolumn{2}{|c|}{$\begin{array}{l}\% \text { of the control } \\
\text { glycemic response }\end{array}$} & & \\
\hline \multicolumn{7}{|l|}{$\begin{array}{l}\text { Type of drink (irrespective of } \\
\text { source of starch food) }\end{array}$} \\
\hline Green tea & 3 & 65 & -23 & $(-29$ to -16$)$ & 0.48 & $26,22,27$ \\
\hline Other teas & 6 & 173 & -19 & $(-27$ to -11$)$ & $0.75^{4}$ & $28,29,30,31,32,33$ \\
\hline Soft drinks & 3 & 86 & -20 & $(-29$ to -11$)$ & 0.0 & $34,35,36$ \\
\hline Coffee & 1 & 35 & -38 & - & - & 22 \\
\hline \multicolumn{7}{|l|}{$\begin{array}{l}\text { Type of food carbohydrate } \\
\text { (irrespective of type of drink) }\end{array}$} \\
\hline
\end{tabular}

${ }^{1}$ For further information about individual study details, see "Supplemental Data" in the online issue. Adjustment to a 6-g dose of RMD was made from the covariance (slope) in Figure 3 for drinks. The dose of $6 \mathrm{~g}$ was chosen to represent a typical amount of RMD in a product.

${ }^{2}$ CIs failing to pass through (or above) zero are significant $P>|z|<0.05$.

${ }^{3} I^{2}$ is the proportional contribution of heterogeneity (among-study variance) to the total variance (within and among studies).

${ }^{4}$ Significant heterogeneity $(P>Q<0.01)$.

tea, other teas, and soft drinks. The amount of RMD used in drinks varied (range: 3-10 g); therefore, for comparative purposes, we adjusted for dose- to $6 \mathrm{~g}$. Attenuation of the glycemic response to meal carbohydrate was evident in each subgroup of drinks and each subgroup of food or available carbohydrate taken with drinks $(P>|z|<0.001)$ (Table 1$)$.

Most of the 16 RCTs that examined the attenuation of glycemic response to starch foods by RMD in drinks (shown at the

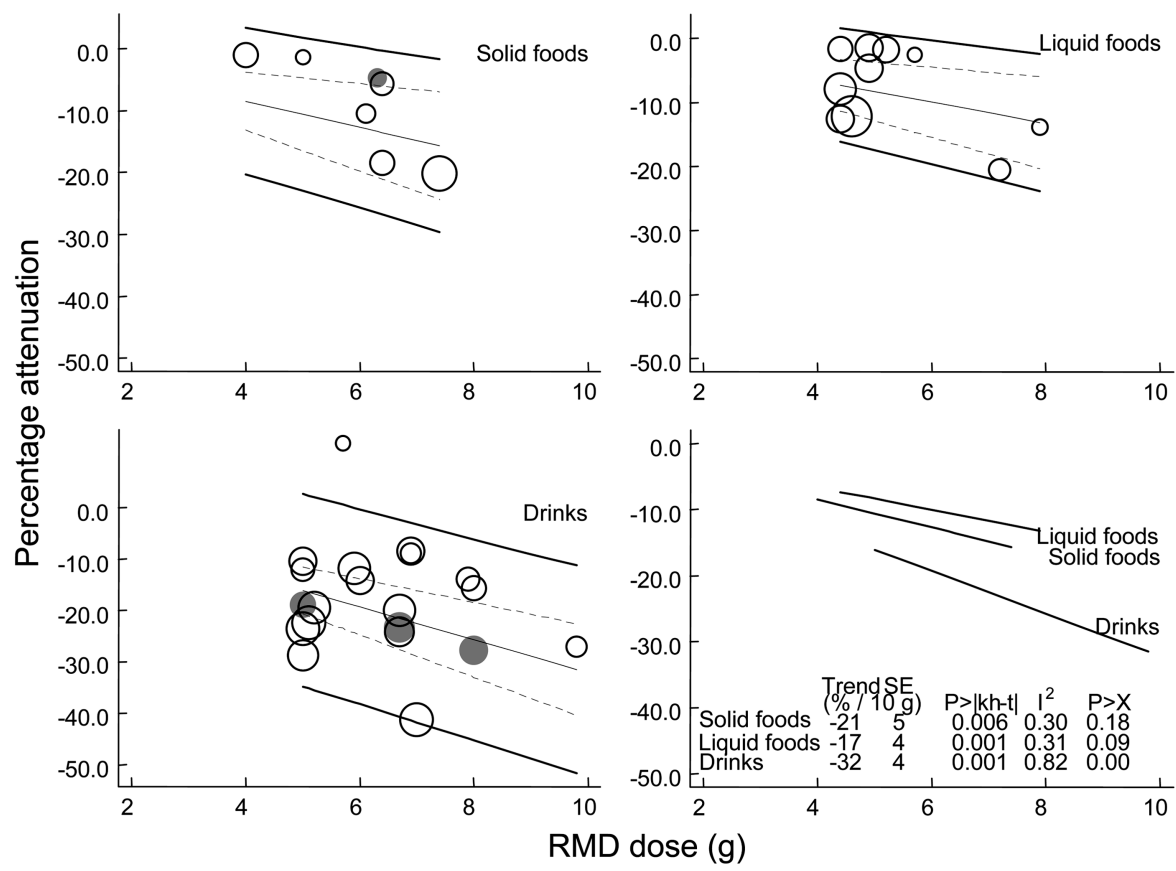

FIGURE 3. Attenuation of the glycemic response to foods: the effect size of resistant maltodextrin (RMD) by dose and by type of foodstuff in which the RMD is presented. Open bubbles represent the included studies; center unbroken line, represents the trend; broken lines, represent $\pm 95 \%$ CIs for trend; outer unbroken lines, represent $\pm 95 \%$ CI for randomized controlled trials (RCTs). Each food group was analyzed separately. Solid foods $(k=6 \mathrm{RCTs}, n=138$, $41 \%$ male): tofu, bread rolls, rice, and wheat noodles. Liquid foods ( $k=10 \mathrm{RCTs}, n=248,41 \%$ male): onion, miso, tomato, clear harusame soups, gruel, and yogurt. Drinks ( $k=16 \mathrm{RCTs}, n=458,33 \%$ male): oolong tea, Ryuto (RY) tea, blended tea, green tea, other teas, coffee, and soft drinks. All meals taken with the drinks were starch based. Gray bubbles represent the controlled studies that were excluded because either randomization was not confirmed or the study designs were not strictly admissible (see Figure 1). 
center of Figure 2) came from 9 similar studies that used 300 or $400 \mathrm{~g}$ boiled rice-glycemic index 85 compared with glucose. The combined mean attenuation was $18 \%(P<0.001)$, both with and without adjustment to a common intake of $6 \mathrm{~g}$ RMD (Table 1, Figure 4). The latter showed that random- and fixedeffects meta-analyses gave similar combined means-to within $1 \%$ of each other. Although heterogeneity was evident $\left(I^{2}=\right.$ 0.378 ), it was half that seen among the larger number of different studies shown in Figure 2 and was no longer statistically significant $(P>0.1)$. For comparison with data in Figure 2, attenuation of the glycemic response to rice by 5-8 g RMD corresponded to a rate of $29 \mathrm{SE} \mathrm{4 \% /10} \mathrm{g} \mathrm{RMD.}$

A trim-and-fill analysis of the data on rice (Figure 3 ) yielded a filled combined random-effects mean of $-21 \%$ ( -26 to $-16 \% ; P>|z|<0.001)$ compared with $-18 \%$ for the unfilled mean and a nonsignificant $(P>|z|=0.24)$ asymmetric bias of $\approx 3 \%$ (ie, -21 less -18 ). The number of studies needed to make a funnel plot symmetrical was 3 . These data were consistent with a publication bias causing underestimation of the effect of RMD, as considered further below.

The time over which blood glucose measurements were made was not critical. Attenuation of the IAUC was similar at all times up to $120 \mathrm{~min}$ and showed no evidence of a lesser effect with time approaching $120 \mathrm{~min}$ (Figure 5).

\section{Attenuation relating to meal composition}

There was no evidence of confounding by variation in macronutrient composition among the 37 RCTs with different meals. Thus, macronutrient composition other than RMD was without significant effect on attenuation of glycemic response by RMD, whether assessed by using either univariate meta-regression or multivariate meta-regression after a backward stepwise procedure. These were examined in addition to the dose of RMD (g/ meal), the weight of meals (130-760 g fresh weight, including drink weight), the energy content of meals (range: 508-3334 kJ), the energy density of meals (range: $3-7 \mathrm{~kJ} / \mathrm{g}$ fresh $\mathrm{wt}$ ), and the protein (range: 0-23 g), carbohydrate (range: 30-173 g), and fat (range: 0-15 g) contents of the meals. Considering all RCTs together, the backward stepwise analysis dropped all compositional determinants other than RMD dose. Dose of RMD was the only significant factor in univariate analysis $(P>|\mathrm{kh}-\mathrm{t}|=0.022$ compared with $P>\mid$ kh- $\mathrm{t} \mid>0.60$ for all these other factors). Confirmation of statistical significance for RMD dose was obtained by using the distribution-free Monte Carlo permutations test with 5000 replications $(P>\mid$ permute $\mid=0.028 \pm 0.002)$.

\section{Attenuation relating to subclinical variations in fasting glycemia and carbohydrate tolerance}

Of the $37 \mathrm{RCTs}$, neither fasting plasma glucose concentration (4.6-6.3 mmol/L) nor carbohydrate tolerance (IAUC/g available carbohydrate) was significantly associated with the degree of attenuation of postprandial glycemia by RMD in either univariate or bivariate analyses with RMD dose $(P>\mid$ kh-t $\mid>0.50)$.

\section{Study quality}

In addition to choosing to include only RCTs in the analyses, we examined whether any deficiency in the conduct or reporting of these studies might be a source of bias in the trends found (Figure 3 ). For example, all RCTs were randomized; therefore, the combined mean residual for this quality item was zero (Table 2; study

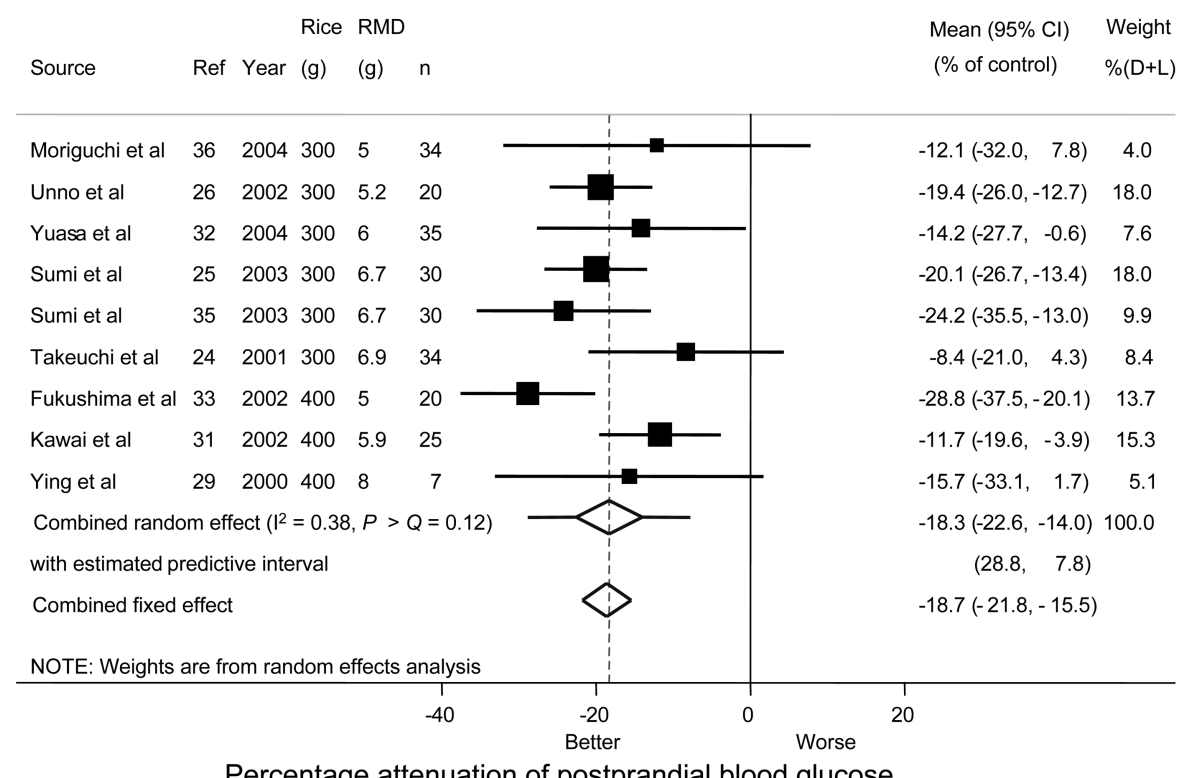

FIGURE 4. Attenuation of the glycemic response to 300 or $400 \mathrm{~g}$ rice by beverages including resistant maltodextrin (RMD) compared with beverages without RMD in placebo-controlled randomized controlled trials (RCTs). $k=9$ studies, $n=235$ adults, $38 \%$ male. Trim-and-fill analysis indicated that 3 studies were needed to achieve symmetry in the funnel plot and favored a greater attenuation of $-21 \%(-26 \%$ to $-16 \%)$ of the control glycemic response; bias on such account $(<3 \%$ of the glycemic response to rice alone) was not significant $(P>|z|=0.24)$. One study (28) was excluded from this analysis as an outlier because its mean was 2.6 SEs from the combined mean. Not excluding the study gave a trim-and-fill combined mean of 21 (16-26)\%, which is not significantly different from the results of the trim-and fill analysis when excluding the study. The lack of difference was attributed to the low weight of this study and the asymmetry it caused being balanced in the parametric trim-and-fill analysis by an additional filling study required to achieve symmetry. $\mathrm{D}+\mathrm{L}$, DerSimonian and Laird. 


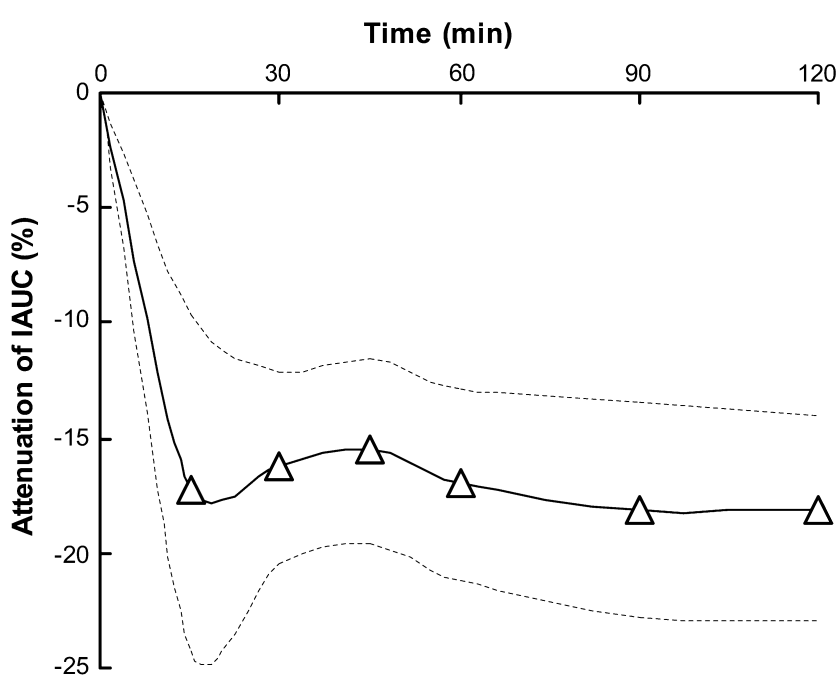

FIGURE 5. Propagation of the value for attenuation of the glycemic response to rice by $5-8 \mathrm{~g}$ resistant maltodextrin (RMD). Curves are the random-effects means $\left(-\Delta_{-}\right)$combined from $k=9$ randomized controlled trials $(n=235$ people, $38 \%$ male) and $\pm 95 \%$ CI of the mean $(-)$. The meta-analysis at $120 \mathrm{~min}$ is shown study-by-study in Figure 4. IAUC, incremental area under the curve.

quality item 1). Not all studies reported were double-blind: 10 were double-blind and 27 were single blind; however, both subgroups had nonsignificant combined mean residuals of $<1 \%$, which indicated negligible investigator bias (Table 2; study quality item 4).

Funding bias was not assessable directly because all of the studies were supported by one type of funding organization (Table 1; study quality item 11). However, the absence of significant investigator bias (Table 1; study quality item 4) and settings bias (Table 1; study quality item 12) would be consistent with a low or negligible funding bias. In addition, we grouped studies into those with authors affiliated to profit-making organizations alone and those that included authors from nonprofit organizations. Neither group had mean residuals that were significantly different from the trends - these being $0.1 \%$ SE $1.4 \%(k=7)$ and $0.5 \%$ SE $1.6 \%(k=30)$, respectively.

Of all the study quality items, there was no significant evidence of a cause of bias due to any of the study quality items or to the total of individual quality items. Study quality item 2 (Table 2) included a single deviant study (28), with a large SD of difference for the treatment effect, which might be attributed to an error due to productivity in this large study. However, because of dilution among the studies in combination with low weighting due to high variance, the study had no significant influence on the overall result (see Sensitivity analysis below). In addition to the univariate observations in Table 2, we examined the study quality items by backward stepwise meta-regression and found no combination of study quality items to be a source of bias in these studies.

\section{Sensitivity analysis}

For drinks with RMD taken with meals ( $k=16$ RCTs) (Figure 3 ), an omission of any one study could have resulted in a combined mean as small as -29 or as great as -34 compared with the value of $-32(\% / 10 \mathrm{~g})$ shown in Figure 3 without an omission. However, no individual study had an influence statistic $\Delta \beta_{i j}>1$; therefore, no study was excluded.
For liquid foods ( $k=10$ RCTs) (Figure 3 ), an omission of any one study could have resulted in a combined mean as small as 14 and as great as -19 compared with the value of $-17(\% / 10$ g) shown in Figure 3 without an omission. However, no study had an individual influence statistic $\Delta \beta_{i j}>1$; therefore, no study was excluded.

For solid foods ( $k=6$ RCTs) (Figure 3), an omission of any one study could have resulted in a combined mean as small as 16 and as great as -23 compared with the value of $-21(\% / 10$ g) shown in Figure 3 without an omission. Again, however, no study had an influence statistic $\Delta \beta_{i j}>1$; therefore, no study was excluded.

\section{Symmetry and asymmetry}

Publication bias can be a significant cause of asymmetry in funnel plots. Because all studies were funded by food industries that may have an interest in the study outcomes, we specifically examined the studies subgrouped by authors, those affiliated with food companies alone, and those affiliated with academic or clinical organizations, with or without coauthorship from one or more scientists in the food industry. Studies authored by scientists from food companies formed a symmetrical funnel plot without heterogeneity (Figure 6; upper panel) studies involving nonprofit organizations formed a funnel plot with marginal asymmetry and significant heterogeneity (Figure 6; lower panel). This is consistent with the reporting of smaller less precise studies, studies imprecise because of high productivity, and possibly a hesitancy to publish imprecise studies with large effects. However, bias resulting from asymmetry in the distribution was not statistically significant (2.7 SE $1.5 \%, P>|z|=0.07$ ) with the apex of the inverse funnel close to the residual null (Figure 6). This is due to the success of weighting individual study results by inverse variance during meta-analyses.

\section{Adaptation to RMD}

Three RCTs $(29,30,56)$ examined the possibility that adaptation might modify the attenuation by RMD of the glycemic response to dietary carbohydrates (Figure 7). Meta-analysis by group, unadapted and adapted, showed no significant heterogeneity (difference) between the adapted and unadapted states $(P>|z|=0.527)$. Group mean attenuation was $22 \%$ in the unadapted state, $20 \%$ in the adapted state, and $21 \%$ for the $5-8 \mathrm{~g}$ RMD used in both groups.

\section{Attenuation of the insulin response}

Six of the RCTs, 3 from one laboratory $(22,26,32,44)$, provided information on attenuation by 5 to $10 \mathrm{~g}$ RMD of the insulin response to dietary carbohydrate (Table 3). The RMD had been presented in various forms - in teas or sugar solutions or in one case yogurt. The sources of available carbohydrate varied among studies - sugars, maltodextrin, and starch foodas did the amount of available carbohydrate (50-130 g). The combined study effects were heterogeneous $\left(I^{2}=0.67, P>\mathrm{Q}=\right.$ $0.008)$, but there were too few studies to address hypotheses about the cause of heterogeneity. Nevertheless, all 6 RCTs showed attenuation of the insulin response to dietary carbohydrate by 5-10 g RMD. The combined mean attenuation of $25 \%$ was both significant and comparable with the attenuation of the glucose 
TABLE 2

Assessment of bias related to study quality items and totals in the randomized controlled trials (RCTs) ${ }^{1}$

\begin{tabular}{|c|c|c|c|c|c|c|c|c|}
\hline \multirow{2}{*}{ Source of potential bias (and notes) } & & \multirow{2}{*}{$\frac{\text { No. of RCTs }}{k}$} & \multicolumn{2}{|c|}{$\begin{array}{l}\text { Combined mean } \\
\text { and } \mathrm{SE} \text { of the } \\
\text { residual } \\
\text { difference } \\
\text { from trend }\end{array}$} & \multirow[t]{2}{*}{$\begin{array}{l}\text { Statistical } \\
\text { significance } \\
\text { of the mean } \\
\text { residual } \\
\text { difference from } \\
\text { zero, based } \\
\text { on the } z \text { test } \\
\qquad P>|z|\end{array}$} & \multirow{2}{*}{$\begin{array}{c}\begin{array}{c}\text { SD of } \\
\text { difference } \\
\text { among } \\
\text { studies }\end{array} \\
\sqrt{\mathrm{k} \times \tau^{2}}\end{array}$} & \multirow{2}{*}{$\begin{array}{c}\text { SE of } \\
\text { treatment } \\
\text { difference } \\
\text { among } \\
\text { studies }\end{array}$} & \multirow{2}{*}{$\begin{array}{c}\begin{array}{r}\text { Among } \\
\text { studies } \\
\text { variance }\end{array} \\
I^{2}\end{array}$} \\
\hline & & & Mean & $\mathrm{SE}$ & & & & \\
\hline \multirow{3}{*}{ 1. Randomization used for allocation } & & \multicolumn{4}{|c|}{$\begin{array}{l}\% \text { of the } \\
\text { control } \\
\text { glycemic } \\
\text { response }\end{array}$} & $\begin{array}{l}\% \text { of the } \\
\text { control } \\
\text { glycemic } \\
\text { response }\end{array}$ & $\begin{array}{l}\% \text { of the } \\
\text { control } \\
\text { glycemic } \\
\text { response }\end{array}$ & \\
\hline & Yes & 37 & 0 & 1 & 0.97 & 9 & 6 & 0.70 \\
\hline & No & - & - & - & - & - & - & - \\
\hline \multirow{3}{*}{$\begin{array}{l}\text { 2. Randomization method considered unbiased } \\
\text { (all with no) } \\
\text { (all with no except reference } 28 \text { ) }\end{array}$} & Yes & 33 & 0 & 1 & 0.98 & 8 & 7 & 0.71 \\
\hline & No & 4 & 5 & 7 & 0.57 & 13 & 10 & 0.56 \\
\hline & No & 3 & 1 & 6 & 0.85 & 10 & 7 & 0.49 \\
\hline \multirow{2}{*}{$\begin{array}{l}\text { 3. Baseline data (blood glucose and insulin) } \\
\text { available and similar across treatments }\end{array}$} & Yes & 37 & 0 & 1 & 0.97 & 9 & 6 & 0.70 \\
\hline & No & 0 & - & - & - & - & - & - \\
\hline \multirow{2}{*}{$\begin{array}{l}\text { 4. Double blinding } \\
\text { (otherwise single blinding allowing potential } \\
\text { for investigator bias) }\end{array}$} & Yes & 10 & 0 & 2 & 0.94 & 7 & 4 & 0.48 \\
\hline & No & 27 & 1 & 2 & 0.97 & 9 & 7 & 0.71 \\
\hline \multirow{2}{*}{$\begin{array}{l}\text { 5. Treatments indistinguishable } \\
\text { (placebo satisfactory) }\end{array}$} & Yes & 37 & 0 & 1 & 0.98 & 9 & 6 & 0.70 \\
\hline & No & 0 & - & - & - & - & - & - \\
\hline \multirow[t]{2}{*}{ 6. Dropouts $<20 \%$ of participants } & Yes & 35 & 0 & 1 & 0.84 & 9 & 7 & 0.70 \\
\hline & No & 2 & -2 & 3 & 0.42 & 4 & - & - \\
\hline \multirow{2}{*}{$\begin{array}{l}\text { 7. Adequate explanation of dropouts } \\
\text { (including mention of zero dropouts) }\end{array}$} & Yes & 37 & 0 & 1 & 0.98 & 9 & 6 & 0.71 \\
\hline & No & 0 & - & - & - & - & - & - \\
\hline \multirow{2}{*}{$\begin{array}{l}\text { 8. Crossover study design was used } \\
\text { (appropriate to acute responses) }\end{array}$} & Yes & 37 & 0 & 1 & 0.98 & 9 & 6 & 0.71 \\
\hline & No & 0 & - & - & - & - & - & - \\
\hline \multirow[t]{2}{*}{ 9. Report addresses potential adverse effects } & Yes & 37 & 0 & 1 & 0.98 & 9 & 6 & 0.71 \\
\hline & No & 0 & - & - & - & - & - & - \\
\hline \multirow[t]{2}{*}{ 10. English language used in article or abstract } & Yes & 35 & 0 & 2 & 0.90 & 10 & 8 & 0.74 \\
\hline & No & 2 & 0 & 6 & 0.95 & 9 & - & - \\
\hline \multirow{2}{*}{$\begin{array}{l}\text { 11. Funding was independent of a } \\
\text { for-profit organization }\end{array}$} & Yes & 0 & - & - & - & - & - & - \\
\hline & No & 37 & 0 & 1 & 0.98 & 9 & 6 & 0.71 \\
\hline \multirow{2}{*}{$\begin{array}{l}\text { 12. Setting was independent of funding } \\
\text { organization (place of study and participants) }\end{array}$} & Yes & 10 & 0 & 2 & 0.98 & 7 & 4 & 0.41 \\
\hline & No & 27 & 0 & 2 & 0.87 & 9 & 7 & 0.75 \\
\hline \multirow{2}{*}{$\begin{array}{l}\text { Potentially the highest quality of the } 37 \text { RCTs } \\
\text { (11/12 possible yeses) }\end{array}$} & Yes & 4 & 1 & 3 & 0.86 & 6 & 0 & 0.00 \\
\hline & No & 33 & 0 & 2 & 0.90 & 9 & 7 & 0.72 \\
\hline Quality range & 10 or 11 & 10 & 0 & 2 & 0.86 & 8 & 5 & 0.53 \\
\hline \multirow[t]{2}{*}{ (no. of yeses from a possible of 12) } & 8 or 9 & 27 & 0 & 2 & 0.91 & 9 & 7 & 0.74 \\
\hline & 6 or 7 & 0 & - & - & - & - & - & - \\
\hline
\end{tabular}

${ }^{1}$ Both individual quality items and the sum of the specified quality items are provided, the former approach being preferred (55). $k$, number of studies contributing to the combined mean; $P>|z|$, level of statistical significance based on the $z$ test; $\tau^{2}$, among-studies variance; $I^{2}$, among-studies variance expressed as a fraction of the sum of $\tau^{2}$ and the within-studies combined $\mathrm{SE}^{2}$.

response. No studies reported information on attenuation of the insulin response in participants adapted to RMD ingested daily.

\section{Adverse responses to $\mathrm{RMD}$}

RMD is fermented; it increases the production of flatus and has potential therefore to contribute to abdominal discomfort (57). Authors for all 37 RCTs report briefly an absence of such discomfort among participants at the doses used in these acute studies.

\section{DISCUSSION}

Low-viscous fiber RMD is produced in 2 phases, initially by roasting starch, when up to $50 \%$ may become resistant to digestion $(15,16,58)$. After RMD is refined, $90 \%$ is assayable as
AOAC fiber, which is expected to be nonglycemic (13). The glycemic and insulinemic responses to RMD alone (0-50 g) in healthy persons is correspondingly low $(15,16,22,30,59,60)$.

Because of the low glycemic response to RMD alone, 3-10 g added to meals containing 30-173 g available carbohydrate would not elevate the glycemic response to a relevant extent. In particular, such an elevation is insufficient to obscure attenuation of the glycemic response to available carbohydrate from a meal. That RMD attenuates postprandial glycemia may be somewhat surprising because RMD lacks the viscosity (12-14) usually considered important for similar attenuation by other fibers, such as guar gum (8-10), arabinoxylan (11), and pectin (61), albeit that the more viscous less palatable guar gum may be more effective among compliant consumers. An absence of gastric or postgastric 

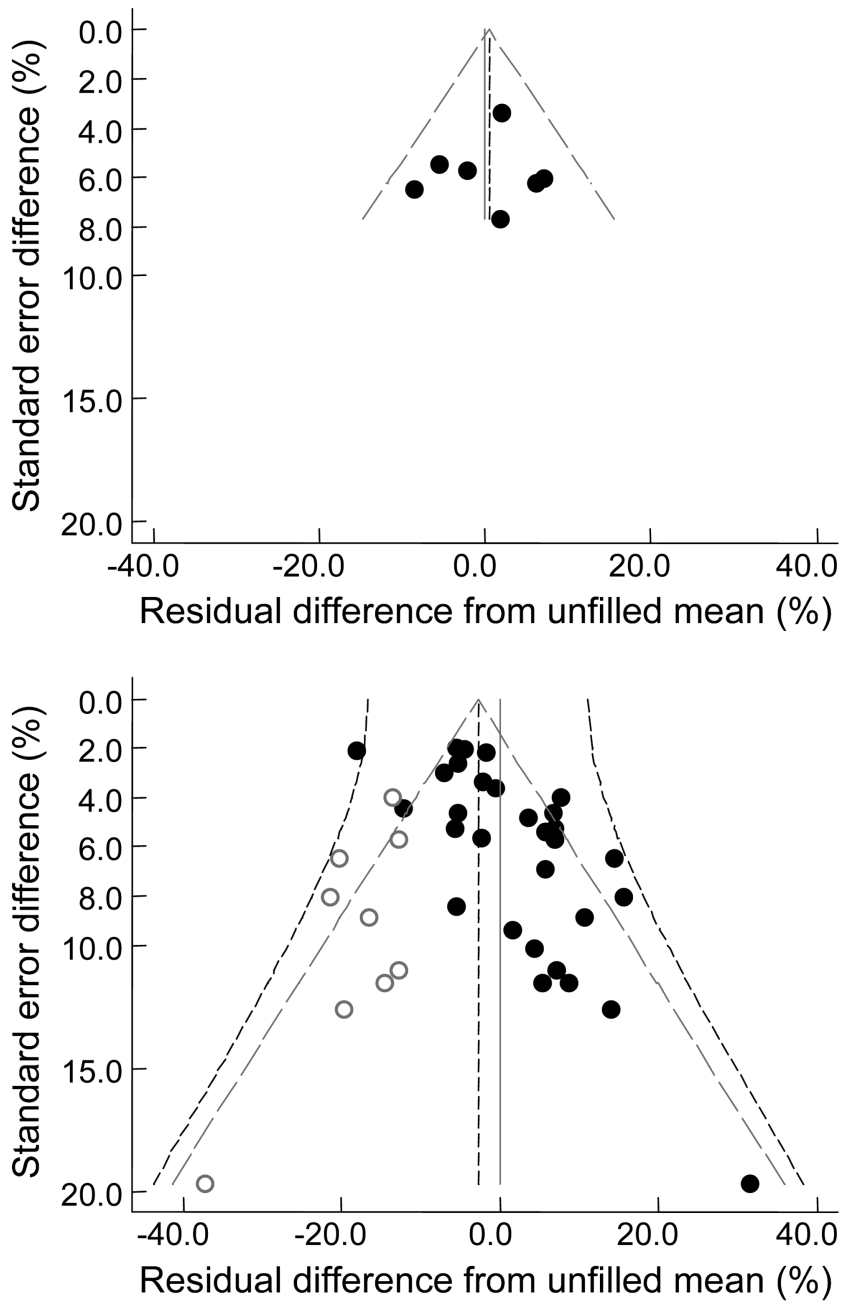

FIGURE 6. Symmetry and asymmetry in study residual differences from trends. Residuals are differences between individual study results and the corresponding trend shown in Figure 3. The upper panel shows studies with authorship from only scientists in food companies $(k=7$, symmetrical without heterogeneity) and from all other studies including academic and clinical authors ( $k=30$, asymmetrical with heterogeneity). Symbols are for individual study means $(-)$ with the addition of nonparametric estimates $(O)$ generated by trim-and-fill analysis to make the distribution symmetrical or to represent missing studies (if assumed to be publication bias). The sloping lines show pseudo 95\% CIs (see Methods) for the fixed effect (gray - - -) and the random effect (black - - -). The vertical lines show the null difference from trend at $\bar{x}=0$ (gray ---) and the combined residual mean $(\bar{x})$ at the center of the fixed or random filled distributions (black - - -), which in the lower panel shows a nonsignificant difference for $\bar{x}$ of -2.8 SE $1.5 \%(P>|z|=0.07)$.

viscosity in vivo is not excluded as a potential mechanism on the basis of the present data. That a fiber of low viscosity before ingestion can be effective is of interest for $\geq 3$ reasons. First, it shows that soluble nondigestible carbohydrate need not always be viscous to lower the blood glucose concentration-a part of the effect even of viscous fiber may be due to factors other than viscosity. Second, nonviscous polysaccharides avoid issues of safety and poor palatability seen with viscous polysaccharides. Third, the range of foods in which nonviscous polysaccharides can be used is wider than for viscous ones.

RMD is more potent in drinks consumed with starch foods than when placed directly into such foods $(P>|\mathrm{kh}-\mathrm{t}|=0.008)$. Plausible mechanisms of attenuation include the following: 1 ) slower gastric emptying, 2) hydrodynamic movement (hurry) of digesta to distal sites of the intestine where absorption may be less rapid, 3) enzyme inhibition, 4) enhancement of the insulin response, 5) binding of factors promoting glycemia in tea or coffee, and 6) degradation, oxidation, or browning of RMD during cooking in foods.

This review establishes that an enhanced insulin response does not occur in response to RMD consumption; rather, it also is attenuated. RMD also attenuates the triacylglycerol response to ingested fat (62), which being structurally different, suggests a mechanism other than enzyme inhibition. Binding of food factors that enhance the glycemic response and that are present in tea and coffee also seems an unlikely explanation. Thus, RMD dissolved in water with refined carbohydrate but without such food factors is also effective. However, such a mechanism cannot be excluded entirely as a contributory factor and may have played a role in a larger effect observed in one study of RMD in coffee and to lesser extent in teas. Whether liquid-phase RMD at doses of 3-10 g per meal can affect intraluminal flow, and thus move digestion distally to a site of slow absorption, is not known at present. Last, RMD is resistant to depolymerization by cooking in water $\left(120^{\circ} \mathrm{C}\right.$ autoclave, $10 \mathrm{~min}$ or $100^{\circ} \mathrm{C}, \mathrm{pH} 2.4$ for $\left.1 \mathrm{~h}\right)$ and resists browning compared with glucose and maltodextrin $\left(100^{\circ} \mathrm{C}\right.$, $150 \mathrm{~min}, 420 \mathrm{~nm}$ ) (Matsutani Co, Ltd, public communicationproduct sheet, 2008); however, such cannot be unequivocally discounted as a reason for loss of potency in lowering the glycemic response in cooked foods. Whatever the mechanisms of attenuation, observations from a minimum of 3 studies required for a meta-analysis indicate the effect to be stable against adaptation to regular exposure to RMD (Figure 7).

The results of the present analyses are supported by a large number of RCTs of similar design and of relatively high quality when judged against many other contemporary nutritional studies in Western journals. In part, this arises because good placebo controls can be prepared for RMD, whereas many nutritional studies are unable to conceal treatments from investigators or participants. Thus, the treatments in all the RCTs were concealed from the participants (at least single blinded). Quality assessment also fairs well against the majority of contemporary nutritional studies; thus, few studies were excluded on the basis of poor study design. For those studies that were excluded, there was evidence of no significant exclusion bias. Moreover, although quality assessment is relatively high for nutritional studies, it was expected to have been underscored here because of the limited prior knowledge of authors to today's reporting standards in combination with the inability of some authors to supply information that was missing from their publications.

Additional strengths of the meta-analytic results were the determination of dose responsiveness and the finding that no study quality item was associated with either a physiologic or statistically significant departure from the trends observed. A relative weakness of the meta-analytic results was that the study qualities were variably below those currently demanded for the best drug studies. However, we attribute this to the fact that the quality of nutritional studies lags behind that of drug studies. A further weakness was the potential for funding bias; all studies were funded by profit-making organizations. On the other hand, there was no significant investigator bias or settings bias, and studies reporting the involvement of academic and clinical organizations yielded results in agreement with those reported by industry scientists alone from the profit-making organizations. Furthermore, 


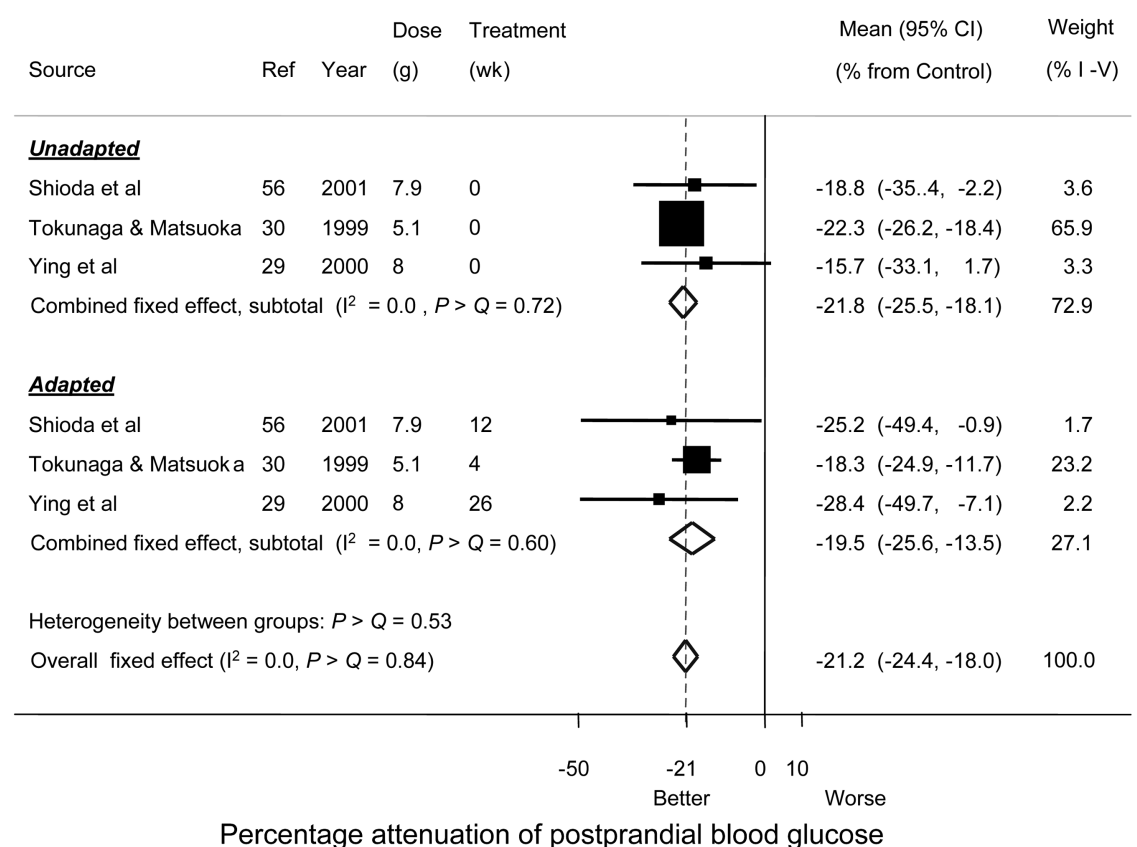

Percentage attenuation of postprandial blood glucose

FIGURE 7. Persistence of the attenuation of the glycemic response by resistant maltodextrin (RMD) up to 26 wk as indicated in the randomized controlled trials. Meals consisted of either noodles and rice $(30,56)$ attenuated with RMD tea compared with tea control or rice alone attenuated with an RMD yogurt drink compared with an RMD-free yogurt drink placebo (29). Observations were for persons unadapted ( 0 wk treatment) or adapted to RMD ingestion for $\geq 4$ wk to $\leq 26 \mathrm{wk}$. The difference between adapted and un-adapted persons was not significant (heterogeneity between groups: $P>Q=0.53$ ). The meta-analysis by group was conducted with fixed effects $\left(I^{2}=0.0\right)$. The effect sizes were significant in both unadapted and adapted persons $(P>|z|<0.001)$. I-V, inverse variance.

heterogeneity and asymmetry of results was missing for studies authored by persons from profit-making organizations alone.

A further strength was that each way of cutting the evidence, by different drink type and by different sources of starch food, always resulted in RMD demonstrating effectiveness for lowering postprandial glycemia. A further strength was that potential confounding due to meals with different diet compositions was not evident; the results appeared to be independent of the amounts of available carbohydrate, protein, and fat in the foods. Furthermore, there was no strong indication that the results were dependent on the type of carbohydrate (refined- or simple- rather than complex-starch foods). However, a weakness was that the mechanism of effect of RMD was far from being understood, although this is not uncommon in nutritional studies.

A limitation of the present studies was that they applied to healthy adult persons consuming foods with a relatively high glycemic index (rice, $\approx 85 \%$; wheat noodles, $\approx 85 \%$; sucrose, $\approx 67 \%$; maltodextrin, $\approx 100 \%$; bread, $\approx 70 \%$; and glucose, $100 \%$ ). Whether the results apply to patients with diabetes or to persons consuming low-glycemic-index foods or taking medications for glycemic control remains to be investigated. Whether soda with RMD added to supply "body" reduces the glycemic response in persons aged $<18 \mathrm{y}$ in the United States who consume high quantities of this beverage should be investigated.

To conclude, we examined a large body of evidence on the attenuation of the glycemic response to various foods and carbohydrate types in response to a practical dose of nonviscous soluble fiber. Information is provided on the IAUCs for glucose in individual RCTs, calculated and published here for the first time together with means and trends obtained by combining results from individual studies. The findings indicate that the consumption of a nonviscous fiber, in this case RMD, by healthy persons attenuates the glycemic response to carbohydrate foods, has a dose-response effect at doses of 3-10 g/meal, and has a stronger attenuating effect when consumed in a drink than when consumed in prepared foods. No confounding factors and no causes of significant bias were observed despite analysis of residuals by study quality items, sensitivity analysis, trim-and-fill analysis, and use of funnel plots.

We thank Yuka Kishimoto for help with the search for non-English language articles and for addressing many questions that arose. Foreign language translations into English were gratefully conducted by Sumiko Kanahori, Shoko Miyazato, Kyoko Inaba, Chieko Hashizume, and Yuma Tani (all from Matsutani Chemical Industry Co, Ltd, Japan). We are grateful to the following persons from Japan for clarifying and providing additional information when necessary: He Fang (Technical Research Laboratory, Takanashi Milk Products Co, Ltd), Ryo Kaned (Odani Kokufun Co, Ltd), Masaharu Ohkawara (Satoen Co, Ltd), Chihiro Kobayashi (SSP Co, Ltd), Kozo Nagata (Ito En, Ltd), Takao Fuse (Kameda Seika Co, Ltd), Syunich Inoue (Shikishima Baking Co, Ltd), Yoichi Fukushim (Nestle Japan Ltd), Hiroshige Kawa (Arkray, Inc), Ryo Sumi (Nikken Sohonsha Corporation), Hirohide Tamura (Fuji-Sangyo), Shigeo Moriguchi (Suntory Ltd, Institute for Health Care Science), Manami Yuasa (Fundamental Research Laboratory, Asahi Breweries, Ltd), Kinya Takagaki and Nobutaka Kusaba (Toyo Shinyaku Co, Ltd), Tatsuichiro Abe and Hajime Gotou (The Nisshin Oillio Group, Ltd), Bunichiro Yasui (Sanwa Kagaku Kenkyusho Co, Ltd), and Jun Sano, Ryoko Tsuda, and Kohji Ohki (Calpis Co, Ltd).

The authors' responsibilities were as follows-GL: designed and conducted the review, conducted the literature search, identified the key questions arising in the literature, synthesized the review, drafted the manuscript, and collected, extracted, managed, and analyzed the data; and TH: conceived the review, communicated with the original authors to obtain missing data identified by GL, helped conduct the literature searches and collect the data, extracted data related to study quality, interpreted the summary data, 
TABLE 3

Attenuation of the incremental insulin area under the curve in response to carbohydrate by resistant maltodextrin (RMD) as indicated in the randomized controlled trials

\begin{tabular}{|c|c|c|c|c|c|c|c|}
\hline \multirow{2}{*}{$\begin{array}{l}\text { Source of } \\
\text { carbohydrate }\end{array}$} & \multirow{2}{*}{$\begin{array}{l}\text { No. of participants } \\
\text { in each study } \operatorname{arm}^{l}\end{array}$} & \multirow{2}{*}{$\begin{array}{l}\text { Carbohydrate } \\
\text { in meal eaten }\end{array}$} & \multirow{2}{*}{$\begin{array}{l}\text { RMD } \\
\text { dose }\end{array}$} & \multicolumn{2}{|c|}{ Individual study attenuation } & \multirow{2}{*}{$\begin{array}{l}\text { Weight of each study } \\
\text { contributing to the } \\
\text { meta-analysis }^{2}\end{array}$} & \multirow[b]{2}{*}{ Reference } \\
\hline & & & & Mean & SE & & \\
\hline & & $g$ & $g$ & \multicolumn{2}{|c|}{$\%$ of the control insulin response } & \multicolumn{2}{|l|}{$\%$ of the total 100} \\
\hline $\begin{array}{l}\text { Starch (rice } \\
\quad \text { and curry) }\end{array}$ & 35 & 125 & $6^{4}$ & -16 & 18 & 10 & Yuasa et al (2004) (32) \\
\hline $\begin{array}{l}\text { Mixed } \\
\text { carbohydrate } \\
\quad(\text { starch, sucrose })^{5}\end{array}$ & 21 & 130 & $7.2^{6}$ & -15 & 9 & 18 & Morita et al (2004) (44) \\
\hline Sucrose & 5 & 100 & $10^{7}$ & -14 & 12 & 15 & Wakabayashi et al (1999) (22) \\
\hline Glucose & 5 & 50 & $10^{8}$ & -40 & 9 & 19 & Wakabayashi et al (1999) (22) \\
\hline \multirow[t]{4}{*}{ Maltodextrin } & 5 & 50 & $10^{9}$ & -46 & 7 & 20 & Wakabayashi et al (1999) (22) \\
\hline & \multicolumn{3}{|c|}{$\begin{array}{l}\text { Combined mean ( } 95 \% \text { CI for mean) } \\
\text { and significance of difference } \\
\text { from zero }\end{array}$} & \multicolumn{2}{|c|}{$-25(-38$ to -11$)$} & \multicolumn{2}{|c|}{$P>|z|<0.001^{10}$} \\
\hline & \multicolumn{3}{|c|}{$\begin{array}{l}\text { Trim-and-fill analysis }{ }^{11} \text { mean (95\% CI } \\
\text { for mean) and significance of difference } \\
\text { from zero }\end{array}$} & \multicolumn{2}{|c|}{$-25(-38$ to -11$)$} & \multicolumn{2}{|c|}{$P>|z|<0.001^{10}$} \\
\hline & \multicolumn{3}{|c|}{$\begin{array}{l}\text { Among-studies variance as a proportion } \\
\text { of the total variance }\left(I^{2}\right)^{12}\end{array}$} & \multicolumn{2}{|c|}{0.67} & \multicolumn{2}{|c|}{$P>Q=0.008^{13}$} \\
\hline
\end{tabular}

\footnotetext{
${ }^{1}$ All had a crossover design.

${ }^{2}$ The relative weights (percentage contribution to the combined mean) of the inverse variance according to random effects.

${ }^{3}$ Present in $190 \mathrm{~mL}$ green tea.

${ }^{4}$ Present in $250 \mathrm{~mL}$ blended tea.

${ }^{5}$ Pastry and jam.

${ }^{6}$ Present in 100 g yogurt.

${ }^{7}$ Added to the sucrose in $150 \mathrm{~mL}$ water.

${ }^{8}$ Added to the glucose in $300 \mathrm{~mL}$ water.

${ }^{9}$ Added to the maltodextrin in $150 \mathrm{~mL}$ water.

${ }^{10}$ Statistical significance of difference from zero attenuation based on the $z$ test.

${ }^{11}$ A nonparametric method of assessing publication bias (53) and the combined mean and CI including an estimate of the possible number of missing studies. Difference between the combined mean and the trim-and-fill mean provide a quantitative estimate of such bias.

${ }^{12}$ Proportion of the total variance (sum among and within study) due to variance among studies.

${ }^{13}$ Statistical significance of heterogeneity (among-studies variance) differing from zero based on the $Q$ test.
}

and revised for comprehension drafts by persons for whom English is not a first language. GL had no part in any of the studies included in the review, was commissioned by Matsutani Chemical Industry Co, Ltd (Itami City, Japan) to lead the process of the review, and is employed by and holds shares in Independent Nutrition Logic Ltd. TH had no part in any of the studies reviewed and is a member of the research staff at Matsutani Chemical Industry Co. Matsutani Chemical Industry Ltd manufactures resistant maltodextrin.

\section{REFERENCES}

1. WHO/FAO. Carbohydrates in human nutrition. Rome, Italy: Food and Agriculture Organization, 1998. (FAO Food and Nutrition paper no. 66.)

2. Livesey G, Taylor R, Hulshof T, Howlett J. Glycemic response and health a systematic review and meta-analysis: relations between dietary glycemic properties and health outcomes. Am J Clin Nutr 2008; 87:258S-68S.

3. Livesey G, Taylor R, Hulshof T, Howlett J. Glycemic response and health a systematic review and meta-analysis: the database, study characteristics, and macronutrient intakes. Am J Clin Nutr 2008;87: 223S-36S.

4. Anderson JW, Randles KM, Kendall CW, Jenkins DJ. Carbohydrate and fiber recommendations for individuals with diabetes: a quantitative assessment and meta-analysis of the evidence. J Am Coll Nutr 2004; 23:5-17.

5. Brand-Miller J, Hayne S, Petocz P, Colagiuri S. Low-glycemic index diets in the management of diabetes: a meta-analysis of randomized controlled trials. Diabetes Care 2003;26:2261-7.
6. Livesey G, Taylor R. Fructose consumption and consequences for glycation, plasma triacylglycerol and body weight: meta-analyses and meta-regression models of intervention studies. Am J Clin Nutr 2008;88: 1419-37.

7. Barclay AW, Petocz P, McMillan-Price J, et al. Glycemic index, glycemic load, and chronic disease risk-a meta-analysis of observational studies. Am J Clin Nutr 2008;87:627-37.

8. Fairchild RM, Ellis PR, Byrne AJ, Luzio SD, Mir MA. A new breakfast cereal containing guar gum reduces postprandial plasma glucose and insulin concentrations in normal-weight human subjects. Br J Nutr 1996;76:63-73.

9. Ellis PR, Dawoud FM, Morris ER. Blood glucose, plasma insulin and sensory responses to guar-containing wheat breads: effects of molecular weight and particle size of guar gum. Br J Nutr 1991;66:363-79.

10. Chuang LM, Jou TS, Yang WS, et al. Therapeutic effect of guar gum in patients with non-insulin-dependent diabetes mellitus. J Formos Med Assoc 1992;91:15-9.

11. Garcia AL, Otto B, Reich SC, et al. Arabinoxylan consumption decreases postprandial serum glucose, serum insulin and plasma total ghrelin response in subjects with impaired glucose tolerance. Eur J Clin Nutr 2007;61:334-41.

12. Wakabayashi S. [The effects of indigestible dextrin on sugar tolerance: I. Studies on digestion-absorption and sugar tolerance]. Nippon Naibunpi Gakkai Zasshi. 1992;68:623-35 (in Japanese).

13. Gordon DT, Okuma K. Determination of total dietary fiber in selected foods containing resistant maltodextrin by enzymatic-gravimetric method and liquid chromatography: collaborative study. J AOAC Int 2002;85:435-44. 
14. Fujiwara K, Matsuoka A. [Improvement of glucose tolerance by lowviscosity, water-soluble dietary fiber, indigestible dextrin.] J Nutr 1995;53:361-8 (in Japanese).

15. Ohkuma K, Matsuda I, Katta Y, Hanno Y. [Pyrolysis of starch and its digestibility by enzymes - characterization of indigestible dextrins.] Denpun Kagaku 1990;37:107-14 (in Japanese).

16. Okuma K, Matsuda I. Indigestible fraction of starch hydrolysates and their determination method. J Appl Glycosci 2002;49:479-85.

17. Ohama H, Ikeda H, Moriyama H. Health foods and foods with health claims in Japan. Toxicology 2006;221:95-111.

18. Saito M. Role of FOSHU (food for specified health uses) for healthier life. Yakugaku Zasshi 2007;127:407-16.

19. Jenkins DJ, Wolever TM, Taylor RH, et al. Glycemic index of foods: a physiological basis for carbohydrate exchange. Am J Clin Nutr 1981;34:362-6.

20. Foster-Powell K, Holt SH, Brand-Miller JC. International table of glycemic index and glycemic load values: 2002. Am J Clin Nutr 2002; 76:5-56.

21. Deeks J, Higgins J, Altman D. Section D. 8: Analysis and presentation of results. Cochrane Reviewers' Handbook 4.2.2. Chichester, United Kingdom: Wiley and Sons Ltd, 2002.

22. Wakabayashi S, Kishimoto Y, Nanbu S, Matsuoka A. [Effects of indigestible dextrin on postprandial rise in blood glucose levels in man.] J Jpn Assoc Dietary Fiber Res 1999;3:13-9 (in Japanese).

23. Ueda Y, Wakabayahi S, Matsuoka A. Effect of indigestible dextrin on blood glucose and urinary C-peptide levels following sucrose loading. J Jpn Diabetes Soc 1993;36:715-23.

24. Takeuchi H, Sano J, Nakamura F, et al. [Effect of a tea beverage containing indigestible dextrin on the blood glucose level after ingestion of starchy food.] J Nutr Food 2001;4:61-9 (in Japanese).

25. Sumi R, Ima K, Mabuchi S, Hasegawa K, Takahashi H. [The suppressive effect of the intake of oolong tea beverage containing indigestible dextrin on the elevation of postprandial glucose level and the safety of its long-term intake.] J Nutr Food 2003;6:141-50 (in Japanese).

26. Unno T, Nagata K, Horiguchi T. [Effects of green tea supplemented with indigestible dextrin on postprandial levels of blood glucose and insulin in human subjects.] J Nutr Food 2002;5:31-9 (in Japanese).

27. Shinohara $\mathrm{H}$, Tsuji $\mathrm{H}$, Seto A. [Effects of indigestible dextrin-containing green tea on blood glucose levels in healthy human subjects.] J Nutr Food 1999;2:52-6 (in Japanese).

28. Ito S, Kusuba N, Kawamura K, et al. [Effects of powdered drink containing indigestible dextrin and Young barley leaf power on post-prandial blood glucose level.] Jpn J Pharmacol Ther 2006;34:945-52 (in Japanese).

29. Ying R, Kawamori R, Fukuwatari Y. [A scientific approach to health preservation medicine: the result and the safety on the long-drinking tea containing indigestible dextrin against borderline diabetes group.] Eastern Med 2000;16:11-8 (in Japanese).

30. Tokunaga K, Matsuoka A. [Effects of a FOSHU (food for specified health use) containing indigestible dextrin as a functional component on glucose and fat metabolisms.] J Jpn Diabetes Soc 1999;42:61-3 (in Japanese).

31. Kawai H, Yamada Y, Sasaki T, Ohbayashi K. [The effect of the intake of green tea beverage and freeze-dried miso-soup (awase-miso) containing indigestible dextrin on inhibition of postprandial hyperglycemia, and the safety of single and long-term intake.] J Nutr Food 2002;5:34-45 (in Japanese).

32. Yuasa M, Yasue M, Ikeda M, Shinoda Y, Sato K, Kondo A. [The effect of tea beverages containing indigestible dextrin on postprandial blood glucose level after single intake and safety in continuous intake.] Jpn Innovative Food Ingred Res 2004;7:83-93 (in Japanese).

33. Fukushima Y, Jun JJ, Kegai K, Takahashi Y. [Effects of blend tea containing indigestible dextrin on post-prandial blood glucose level and safety of long-term administration.] J Nutr Food 2002;5:109-16 (in Japanese).

34. Mizushima N, Chiba Y, Katsuyama S, Daigo Y, Kobayashi C. [Effect of indigestible dextrin-containing soft drink on blood glucose levels in healthy human subjects.] J Nutr Food 1999;2:17-23 (in Japanese).

35. Sumi R, Ima K, Mabuchi S, Hasegawa K, Takahashi H. [The suppressive effect of the intake of soft drink containing indigestible dextrin on the elevation of postprandial blood glucose level and safety of its long-term intake.] J Nutr Foods 2003;6:89-98 (in Japanese).

36. Moriguchi S, Kusumoto A, Shibata H, et al. [The suppressive effect of the intake of beverages containing indigestible dextrin on the rise of post-prandial blood glucose level.] Jpn Innovative Food Ingred Res 2004;71:63-2004 (in Japanese).

37. Takeyasu H, Suzuki T, Sakamoto H, Muraoka T, Imamura Y, Shionoya $\mathrm{K}$. [Effect of cooked rice containing indigestible dextrin on postprandial blood glucose level and safety of its long-term ingestion.] Jpn Innovative Food Ingred Res 2006;9:37-45 (in Japanese).
38. Fuse T, Kumagai T, Watanabe T. [Effect of cooked rice containing indigestible dextrin on postprandial blood glucose level and the safety of eating it in the long term.] J Nutr Food 2002;5:47-53 (in Japanese).

39. Fuse T, Takano K, Kumagai T, Watanabe T. [Effect of cooked rice containing indigestible dextrin on postprandial blood glucose level in healthy human subjects.] J Nutr Food 2002;5:69-74 (in Japanese).

40. Inoue T, Teramoto K, Watanabe M, Yamada M, Sano M. [Attenuation effect of bread containing indigestible dextrin on elevation of postprandial blood glucose level and its safety in long-term ingestion.] J Jpn Clin Nutr 2005;26:281-6 (in Japanese).

41. Uno K, Takagi K, Akaza M, Takagi N, Yoshio N, Maeda I. [Effect of indigestible dextrin-containing tofu on blood glucose levels in healthy human subjects.] J Nutr Food 1999;2:35-31 (in Japanese).

42. Yaginuma Y, Kishimoto Y, Hayashi N, Sugano S. [The effect of the intake of soba containing indigestible dextrin on postprandial blood glucose level in healthy humans.] J Nutr Foods 2004;7:21-33 (in Japanese).

43. Ikeguchi M, Ito S, Kamiya T, et al. [Effect of soup powder containing indigestible dextrin on post-prandial blood glucose level and safety of long-term intake.] J Jpn Council Advanced Food Ingred Res 2006;9: 57-64 (in Japanese).

44. Morita H, Fang H, Kubota A, et al. [Effect of yogurt containing indigestible dextrin on blood glucose and other blood components.] Jpn Innovative Food Ingred Res 2004;8:33-42 (in Japanese).

45. Kishimoto Y, Wakabayashi S, Yuba K. [Effects of instant miso-soup containing dextrin on moderating the rise of postprandial blood glucose levels, and safety of long-term administration.] J Nutr Food 2000;3: 19-27 (in Japanese).

46. Kawai H, Sasaki R, Ohbayashi K. [The effect of the intake of freeze-dried rice gruel (egg) containing indigestible dextrin on postprandial hyperglycemia, and safety at its long-term intake.] Health Sci 2005;21:61-8 (in Japanese).

47. Kawai H, Kubo M, Saski R, Ohyayashi K. Effect of intake of freeze-dried tomato soup and harusame soup containing indigestible dextrin on inhibition of postprandial hyperglycemia and on safety at their longterm intake. J Jpn Council Advanced Food Inged Res 2005;8:81-91.

48. Kawai H, Takayama K, Sasaki T, Ohbayashi K. [The effect of the intake of freeze-dried miso-soup (white miso) and Japanese clear soup both containing indigestible dextrin on inhibition of postprandial hyperglycemia, and the safety at their long-term intake.] J Nutr Food 2003;6:129-39 (in Japanese).

49. DerSimonian R, Laird N. Meta-analysis in clinical trials. Control Clin Trials 1986;7:177-88.

50. Knapp G, Hartung J. Improved tests for a random effects metaregression with a single covariate. Stat Med 2003;22:2693-710.

51. Higgins J, Thompson S. Controlling the risk of spurious findings from meta-regression. Stat Med 2004;23:1663-82.

52. Sterne JAC, Egger M. Funnel plots for detecting bias in meta-analysis: guidelines on choice of axis. J Clin Epidemiol 2001;54:1046-55.

53. Duval S, Tweedie R. A nonparametric "trim and fill" method of accounting for publication bias in meta-analysis. J Am Stat Assoc 2000;95:89-98.

54. Higgins JPT, Green S. eds. Cochrane handbook for systematic reviews of interventions. Version 5.0.0. February 2008. The Cochrane Collaboration, 2008. Available from: www.cochrane-handbook.org (cited 15 February 2008).

55. Juni P, Witschi A, Bloch R, Egger M. The hazards of scoring the quality of clinical trials for meta-analysis. JAMA 1999;282:1054-64.

56. Shioda N, Shimizu M, Shimizu Y, et al. [Effects of yogurt drink containing indigestible dextrin on postprandial blood glucose levels in Japanese healthy volunteers.] J Nutr Food 2001;4:7-18 (in Japanese).

57. Ohkuma K, Takahashi R. Development and application of low caloric modified starch. Tech J Food Chem Chem 1990;6:62-7.

58. Okuma K, Matsuda I. Production of indigestible dextrin from pyrodextrin. J Appl Glycosci 2003;50:389-94.

59. Kawasaki F, Matsuda M, Hiramatsu T, et al. [Efficacy of tea drink containing indigestible dextrin.] J Nutr Food 2000;3:65-72 (in Japanese).

60. Shoya H, Masuo K, Shinichiro T, Shimada Y, Shioya K. The inhibitory effect on the postprandial increase in blood glucose exerted by a powdered beverage containing indigestible dextrin, and its safety in over ingestion and long-term ingestion. J Nutr Food 2004;7:31-41.

61. Siddhu A, Sud S, Bijlani RL, Karmarkar MG, Nayar U. Modulation of postprandial glycaemia and insulinaemia by pectin in mixed nutrient combinations. Indian J Physiol Pharmacol 1989;33:77-83.

62. Kishimoto Y, Oga H, Tagami H, Okuma K, Gordon DT. Suppressive effect of resistant maltodextrin on postprandial blood triacylglycerol elevation. Eur J Nutr 2007;46:133-8. 